\title{
EMPLOYMENT EXPERIENCES OF POLISH MIGRANT WORKERS IN THE UK HOSPITALITY SECTOR
}

This is the accepted version, without proof corrections. The final version is due to appear in Tourism Management, Volume 32, 2011, doi:10.1016/j.tourman.2010.08.013. If citing please consult the corrected published version.

Hania Janta ${ }^{a}$

Adele Ladkin ${ }^{\mathrm{b}, *}$

Lorraine Brown ${ }^{c}$

Peter Lugosi ${ }^{d}$

aBournemouth University, School of Tourism, Talbot Campus, Fern Barrow, Poole, Dorset. BH12 5BB. UK. hjanta@bournemouth.ac.uk

${ }^{\mathrm{b} H o n g}$ Kong Polytechnic University, School of Hotel \& Tourism Management, Hung Hom, Kowloon, Hong Kong SAR, China.hmladkin@polyu.edu.hk

'Bournemouth University, School of Tourism, Talbot Campus, Fern Barrow, Poole, Dorset. BH12 5BB. UK. Ibrown@bournemouth.ac.uk

dBournemouth University, School of Tourism, Talbot Campus, Fern Barrow, Poole, Dorset. BH12 5BB. UK.plugosi@bournemouth.ac.uk

Corresponding author

*E-Mail Address: hmladkin@polyu.edu.hk

\section{Abstract}

The research explores the experiences of Polish migrant workers in the UK hospitality sector. It reports quantitative and qualitative empirical data on the migrants' reasons for entering the hospitality workforce and their subsequent employment experiences. The findings reveal the main motive for entering employment in hospitality is for self development as migrants wish to use and learn foreign languages, gain work experience and receive other benefits that the sector provides. These self development opportunities are viewed as a means to improve career prospects in the UK or upon return to Poland. Once in the sector, positive experiences associated with hospitality employment include opportunities to meet people and work in a lively environment. Negative aspects relate to working conditions, low pay, physically demanding jobs, discrimination and management behaviour. The research suggests that certain practices and working conditions in the sector pose an obstacle to the long term commitment of migrant workers. Suggestions for the management of migrant human resources are outlined. 


\section{Keywords}

Hospitality employment; migrant workers; Poland

\section{Background}

As a consequence of EU enlargement in May 2004, the UK has experienced a rapid influx of migrant workers, with Poland as the country of origin dominating arrivals (Janta \& Ladkin, 2009). Although accurate figures are difficult to obtain, there are an estimated 610,000 Polish workers registered as employed in the UK (Home Office, 2009). It is widely recognised that these figures are underestimated, with variations reported by different agencies (Lyon \& Sulcova, 2009). Records for the Accession Monitoring Report (Home Office, 2009) show that a total of 965,000 applicants applied to register to the Workers Registration Scheme between $1^{\text {st }}$ May 2004 and $31^{\text {st }}$ December 2008, with the highest proportion (66\%) coming from Poland. By sector, in total 171,940 registered migrants are employed in hospitality and catering and 109,205 of those are of Polish nationality. A debate on numbers notwithstanding, the UK hospitality sector has absorbed large number of Polish migrants into the workforce in recent years.

In tourism studies, Poles are recognised as the largest group of international workers in the UK (Baum, Dutton, Karimi, Kokkranikal, Devine \& Hearns, 2007; Devine, Baum, Hearns, \& Devine, 2007a, 2007b; Evans, Wills, Datta, Herbert, Mcllwaine \& May, 2007). As with any influx of foreign employees, changes in the receiving countries workforces have been reported, with migrant workers having economic, social and cultural effects at the destination. For example, in the case of Polish hospitality workers in the UK, Janta and Ladkin (2009) outline the social implications in terms of workers leaving existing ties and social support structures and making new relationships in the host destination. Culturally, the workers bring with them their own specific style of working. In other examples the influx of migrant workers has resulted in such workplace diversity that traditional imagery often used in destination marketing is not a true reflection of the situation, as in the case of Ireland (Baum, Hearns, \& Devine, 2008:6). In many instances, the implications of the movement of large numbers of people with different backgrounds has a profound influence on all social and cultural aspects of host societies (Kinnard, Kothari, \& Hall, 1994). The departure of workers across international boundaries also has an impact on the migrants' home country. The exodus of workers who leave may result in labour market gaps, conversely human capital is subsequently gained if migrants return to their home countries. 
In the UK, hospitality employers have reported positive stereotypical assumptions of Polish workers, which include having a good work ethic and commitment and acceptance of low wages (McDowell, Batnitzky, \& Dyer, 2007; Matthews \& Ruhs 2007; Anderson, Rhus, Rogaly, \& Spencer, 2006). Furthermore, it has been stated that businesses have come to rely on migrant workers in the hospitality sector and even prefer them to British workers (Matthews \& Ruhs, 2007a). Lyon and Sulcova (2009) indicate that within the hospitality industry, the general view towards the influx of migrant workers is positive as they have a better work ethic than their British counterparts, a positive attitude to work and more skill and experience than UK nationals. The nature of hospitality, with its significant turnover rates and irregular working hours drives the sector towards a constant need for more workers, of which it seems there is an unlimited supply. These needs create employment opportunities for migrant workers due to the labour shortages the UK hospitality sector faces. Given the widely accepted positive effects that the Polish migrant workers have brought to the UK hospitality industry, the management of these human assets has significance for the longer term development of the sector.

Set against this background, our paper explores the reasons for Polish migrant workers coming to the UK and entering employment in hospitality. Once in the sector, their subsequent views and experiences of employment in the sector are outlined, and human resource management implications are discussed.

The focus of our paper is on migrant worker experiences. However, there is a valid criticism by Mackenzie \& Forde (2009) that migration employment studies often ignore the role of employers, other labour market institutions and broader regulatory constraints. Whilst this is not the main focus of our research, we aim to illustrate that the features of the hospitality sector provide a framework for certain conditions and employer needs that have a significant influence on migrant experiences, thus acknowledging the role of employers and wider labour market issues.

\section{Literature Review}

\subsection{Tourism and Labour Migration}

Tourism employment has particular characteristics arising from the spatial and temporal boundaries of tourism consumption (Shaw \& Williams, 1994). The extent to which the production and consumption of tourism generates migration flows rather than relying on the local labour market is a function of the scale of demand, the nature of the demand in terms of skill and educational 
requirements, and the speed of tourism development (Hall \& Williams, 2002). As a consequence, migration into tourism employment has predictable patterns and is not a random occurrence, except possibly in the context of new forms of mobility where migrants whose love of place has over-ridden the logic of labour market material incentives (Williams \& Hall, 2002:1). Straggling international boundaries and the worlds of work and leisure, these new forms of mobility constitute and are the results of globalisation (Held, 2000). At its simplest level, the rationale accounting for migration into tourism labour markets is it serves to fill both absolute and skill shortages of labour, thereby reducing labour market pressures including wage inflation issues. However, migration into tourism employment is a complex phenomenon with migration flows being shaped by a complex combination of self-selection and out-selection mechanisms (Beine, Docquier \& Ozden, 2009).

Despite the difficulties involved in attempting to unravel the complex tourism and labour migration relationship, there is little doubt that tourism employment is an important component and driver of human mobility. The production and consumption of global labour along with goods and services is an important factor with respect to mobilities (Hall \& Williams, 2002). Despite the criticism by Coles, Duval \& Hall (2005) that tourism studies have yet to embrace wider perspectives of mobility, these being, for example, engagement with mobile labour markets, commuting, and migration and diasporas as suggested by Franklin and Crang (2001), the spatial movement of individuals for tourism is a significant area of research. Exploring the range of mobilities undertaken by individuals as opposed to tourists is seen as one of the ways in which tourism studies connects to mobility theory (Coles et al. 2005). Individual mobility is the premise adopted in this research.

Whilst individual mobility facilitates an understanding of the patterns of and experiences of migrant workers, it cannot tell the whole story. The socio-economic context behind individual mobility is a vital part of understanding the experiences, attitudes and aspirations of migrant workers (MacKenzie \& Forde, 2009). They rightly argue that the socio-economic context in which employers make decisions and migrant workers exist are micro level processes that occur within a wider framework, which includes the broader regulatory context. Set within the context of increasing freedom of movement for labour within the EU to meet shortages across a range of jobs, the reality is migrant workers are more likely to work in lower paid jobs for which they are overqualified (Mackenzie \& Forde, 2009). There are different explanations for this; however the role played by employers and regulatory frameworks is significant (Rodriguez, 2004). Meeting labour market shortages and cost minimisation are often cited as reasons for employing migrant workers. Employers may recruit directly from abroad and will often reap the benefits of recruiting workers with skills higher than the job requirements (Fellini, Ferro, \& Fullin, 2007; Rodriguez, 2004). Linked to this are the different 
stereotypes of attitudes towards work commonly perceived by employers as migrant are often seen as harder working than local populations (Dench, Hurstfield, Hill \& Akryod, 2006). However, it is argued that such preconceptions of 'hard work' and 'workers attitude' ignore the socio-economic context in which migrant workers exist (MacKenzie \& Forde, 2009:145), as through a natural process of adaptation, workers attitudes may change over time to reflect the norms of the local population (Bauder, 2006). Therefore, the benefits are only temporary and for those who settle into permanent residency, the willingness to accept low pay and low status work diminishes over time (Knocke, 2000). Considering the characteristics of the hospitality industry, the short term nature of work favours employers who rely on a constant turnover of unskilled employees, of which migrants form a significant group. The expectations of both employers and employees are clearly linked, and are likely to have an impact on the experiences of both.

To summarise, the mobility of migrant workers is a complex mix of macro level frameworks, micro level employer strategies, and individual freedom and choices. Each of these will have an influence on migrant experiences. It has been correctly stated by Lucas and Mansfield (2008) that "it is impossible to generalize the experiences of migrant workers, which may vary from working illegally under exploitative terms and conditions, to working in highly paid, rewarding and skilled jobs" (p.7). Furthermore, the research into the lives and experiences of migrant workers is not without problems, specifically in terms of data collection methods and availability (Phillimore \& Goodson, 2008). These constraints notwithstanding, the paper aims to shed light on migrant experiences within the hospitality sector.

\subsection{Migration and hospitality workers}

The hospitality industry has historically relied on migrant workers (Christensen-Hughes, 1992; King, 1995; Baum, 2006; 2007). The hospitality workforce is characterised by a reliance on particular types of workers who are associated with being marginalised within secondary labour markets; specifically women, students, ethnic minorities, young people and migrants (Lucas \& Mansfield, 2008). Migrants arriving in the UK find jobs in hospitality for a number of reasons, including higher wages in this sector than in their home countries and opportunities to improve English language skills which are valued for further career development. Employers are willing, and some instances actively seek to employ migrants to fill the jobs unwanted by locals (Wood, 1992), therefore it is a mutually convenient relationship. King (1995) states that "the tourism and hospitality industry is a major source of jobs for immigrants" (p.177), and the lack of qualifications or skills makes it 'open' to many different types of immigrants, for example, economic migrants, students, and those seeking 
migration to urban areas. One distinct group of migrants employed in tourism are students who take overseas working holidays. According to King (1995), these migrants, usually from Eastern Europe, experience a sample of life in 'Western Europe' but are also able to earn money to support their studies back in their home country. Others may belong to the category of 'migrant tourism workers' defined by Bianchi (2000) and Uriely (2001). These are migrants who go abroad in order to make a living but also to have entertainment and gain life experiences. Migrant tourism workers combine work with a casual lifestyle by engaging in seasonal employment in tourism. According to Bianchi (2000), they tend to be EU citizens and work in the Mediterranean in the resorts, clubs and bars. Recent research into Polish migrant workers to a large extent confirms that the EU citizens take up jobs in this sector of employment (Janta \& Ladkin, 2009; Lyon \& Sulcova, 2009). However, those employed as hospitality workers may also be backpacker tourists, those having a 'Gap Year' or 'Big Trip' (Duncan, Scott \& Baum, 2009). In this regard, complex mobilities are involved as the hospitality workers become both guests and employees. Finally, monetary rewards have also been reported as a motivation for entering the tourism industry (Dermody, Young, \& Taylor, 2004; Simons \& Enz, 1995).

Much of the migration into hospitality jobs is recognised as temporary. It has been argued that "for most employees, the hospitality sector is not a career option, but rather a preparation for a career in another section of the economy" (Riley, Ladkin, \& Szivas, 2002:21) and "a mere stopover to something better" (Wildes, 2007:7). Hospitality employment is considered to be mostly suitable for young people, students and migrants, since in most cases, it is a temporary solution that opens the door for different career paths in the future. This is combined with unwillingness by employers to develop human capital, largely due to associated costs or a lack of need. Due to the large number of students engaged in employment either during or after their educational programmes, recent studies on the international hospitality workforce have pointed out "an excellent level of educational attainment among respondents relative to the perceived demands of the job" (Devine et al, 2007a:339). This mismatch between qualifications and the jobs performed helps to account for migrants' temporary presence in the sector and there is a view that the most talented people will leave the sector (Lucas, 2004). In the case of Polish workers, the first signs are emerging that many of the migrants are beginning to return home, largely as the economy of Poland improves, job opportunities in the UK decline and the strength of the Euro makes the UK a less attractive employment option, confirming the temporary nature of the migration.

Hospitality employers could in theory draw upon labour from a wide variety of sources, but for cost minimisation strategies and flexibility they rely heavily on young workers (mainly students), female and migrant workers (Baum et al. 2007). In terms of migrants from the EU countries, employers get 
'more for their money' by recruiting migrant labourers who are over qualified and over skilled for their roles they carry out (Dench et al. 2006). Linked to this is profit maximisation whereby marginal workers are employed at rates of pay that do not reflect their skill levels of qualifications (Lucas \& Mansfield, 2008). Additionally, migrant workers may accept work and conditions of employment that British workers would not tolerate (Lucas \& Mansfield, 2008). Worker attitude and worker ethic are also crucial in making the employment of migrant workers an attractive option for employers (Dench et al. 2006).

In attempts to understand why many migrants take up employment in tourism, the sociological concept of orientations to work developed by Goldthorpe, Lockwood, Bechhofer and Platt (1968) has been used in three research studies. Each study offers an insight into migration into the hospitality sector and their contexts help explain the current phase of Polish migration into the UK hospitality workforce. Particularly, the situation of the Hungarian labour market described by Szivas and Riley (1999) at the end of the 80s could be comparable with the situation of Poles looking for work outside Poland in 2004. In both countries, individuals were separated from their education and experience due to political change and unemployment. Whilst these studies are linked by orientations to work (Goldthorpe, Lockwood, Bechofer \& Platt; 1968). Goldthorpe et al. 1968) differences in context are evident. The significance of the socio-economic context highlighted by Mackenzie and Forde (2009) is a major influence on migrant choice of employment.

The first of these studies by Szivas and Riley (1999) conducted a study of mobility patterns into tourism during the 1990s in Hungary, when the country was transforming from communism to capitalism. Their research revealed that those who decide to enter tourism come from a variety of industries, confirming the assumption that many jobs in the hospitality sector do not require specific skills. Szivas and Riley (1999) claimed that tourism can be for many 'a refuge sector', playing the role of 'any port in a storm', where 'tourism workers appear to come from a wide and unconnected set of occupations' (p. 748). In other words, tourism was not necessarily a 'chosen' occupation, but rather was something that could be obtained relatively easily in times of economic transition and mass migration. The socio-economic situation in Hungary at the time offered mobile employees a constrained choice of alternative occupations and the tourism sector offered unskilled occupations that presented few barriers to entry.

The second study was later replicated by Szivas, Riley and Airey (2003) using a different setting where major socio-economic changes were not present. The data collected in urban and rural location in the UK; Somerset and Coventry respectively. It was found that the industry as a refuge sector could account for the younger sample only. The survey revealed that people who were forced 
to change their jobs found work in the tourism industry because they were attracted by the image of tourism. Their main motives for the mobility into tourism were dealing with people and having business skills that could be used in tourism. Szivas, Riley and Airey claim that: 'Tourism is an accommodating industry as it offers a wide range of jobs with diverse human capital requirements' (2003:66). This indicates that tourism does have some attractive opportunities, and is not just the occupation many will follow in the absence of anything else.

In the final study on labour migration, Vaugeois and Rollins (2007) explored the concept of labour mobility in the Canadian context. The findings revealed that most workers enter the tourism sector from various industries that are not necessarily experiencing decline. Again, in this case, tourism is attractive in its own right, and indeed satisfaction with tourism employment turned out to be high. The strongest motivational forces in this research were lifestyle and entrepreneurial opportunities. This finding in part rejects the 'refuge option', although it was still regarded as important within the sector.

Migration into hospitality can therefore be motivated by many different factors, including orientations to work, economic and social factors. However, it is not always possible to isolate one specific cause as in reality a combination of influential factors may work together. Certainly individual motivations for working in the sector will influence subsequent experiences, as will the socio-economic context behind the employers' use of migrant workers. To date, little research has been undertaken into the temporary nature of the migration and how this impacts upon both the individuals and their country of origin on returning home. Reasons for entering the occupations are better understood.

\subsection{Features of Hospitality Employment}

Lucas and Mansfield (2008) identify six generic features of hospitality that directly affect employment. These are; an unpredictable and ad-hoc demand for services, a high level of customer contact, low levels of labour productivity, low wages across a range of occupations, high rates of labour turnover and high levels of hard to fill vacancies.

There is little doubt that the features of hospitality employment and specific jobs will influence the migrant workers' experience. Working conditions, hours, tasks, pay and human capital requirements have considerable bearing on an individuals' experience. 
Jobs in the hospitality industry have been regularly condemned for their nature, status and conditions. Tourism and hospitality employment is characterised by a number of repeatedly cited features, summarised by Walmsley (2004) as: low paid, low skilled, having a negative image, parttime and seasonal, with poor management and lacking a clear career path. Baum (2006) adds they are often dirty jobs, involve physical work, are monotonous and boring and are characterised by long and unsociable hours. Furthermore, the working hours of hospitality employees is usually the time when others have their leisure, thus the demand cycle is anti social (Baum, Amoah \& Spivack, 1997). The jobs themselves are in poor working conditions, are highly pressurised and often based on splitshifts. Such jobs are considered non conducive to a healthy work life balance (Wong \& Ko, 2009; Karatepe \& Uludog, 2007) that make workers susceptible to stress (Faulkner \& Patiar, 1997). Therefore, it is not surprising that Lucas (2004) termed hospitality employment across the globe as 'vulnerable'. Many migrant workers may accept employment in some of the worst jobs, and are often the least protected in terms of employment rights which may leave them open to exploitation. MacKenzie and Forde (2009) argue that labour market strategies used by employers, other labour market institutions and broader regulatory constraints are instrumental in maintaining certain labour market conditions. Hospitality employment certainly features many of the characteristics associated with the secondary sector of segmented labour markets, which typically is where migrant labour dominates.

One of the commonly cited features of tourism and hospitality employment is that it is low paid (Walmsley, 2004; Riley, Lockwood, Powell-Perry \& Baker 1998; Riley, Ladkin, \& Szivas, 2002; Wood, 1992; Choy, 1995; Lucas, 2004). Remuneration is an important element of any job as it is related to worker status and it can affect motivation and commitment to work (Lucas 2004). Indeed may studies found that wages were the most important motivational factors among hospitality employees (Simons \& Enz 1995; Dermody et al \& Taylor, 2004; Wildes 2007). Furthermore, empirical studies revealed that low pay in hospitality is the most important category contributing to dissatisfaction (Lam, Zhang, \& Baum, 2001) and subsequently, leads to the decision to leave the sector (Walmsley 2004; Dermody et al \& Taylor, 2004). In the UK, the hospitality sector is considered the worst paid sector after agriculture (Baum, 2007).

In addition to the realities of the job, the sectors' ability to attract migrant workers relies on its perceived image. Although the projected image of tourism and hospitality employment may not entirely reflect the reality, it is vital as it affects the recruitment of new and the retention of existing employees (Baum, 2006). On the one hand, associated with low status, tourism and hospitality jobs are described as occupations for drifters or stigmatised people (Saunders, 1981), marginal people 
(Mars, Bryant \& Mitchell, 1979), or employees with alcohol problems (Wood, 1992). Other studies claimed that there is a stigma attached to service work (Wildes, 2005; 2007) which is negatively correlated with the intention to stay and to recommend a job in the restaurant industry. Rowley and Purcell (2001) argue that there are some false images (for example, over glamorised TV celebrity chefs) of hospitality work that consequently lead to labour turnover as expectations are unmet. Researchers have also explored tourism and hospitality undergraduate students' attitudes towards the industry. Kuslavan and Kuslavan (2000) found that students in Turkey had a negative image of the industry after they gained practical experience. In agreement with the study, Jenkins (2001) found in his study of Dutch and British students that as the degree progresses, students' desire to search a job within hospitality diminishes. Finally, Richardson (2008) revealed that students in Australia do not believe that the industry offers them a career. From these examples, students do not have a favourable image of the industry and do not regard it as a serious career option.

In contrast, there are positive images of the sector related to 'the glamorous side' such as people orientation, the use of foreign languages, travel and variety that motivate people to take up jobs (Szivas, Riley, \& Airey, 2003; Riley, Ladkin, \& Szivas, 2002). Baum (2007) reports that 'cool' work is associated with style, fashion and consumer branding; related to work in clubs and boutique hotels, while 'uncool' work includes the work of drudgery in the sector; jobs in cleaning and what was 'cool' in the past but not anymore; working for low cost airlines. Research carried out by Choy (1995) in Hawaii shows a high level of satisfaction with jobs in air transportation, the hotel sector and eating and drinking places. The majority of respondents were satisfied with their jobs and the quality of tourism employment was outlined. A high level of job satisfaction was also found among pub workers (Riley, Lockwood, Powell-Perry \& Baker 1998). In agreement, Riley, Ladkin and Szivas' (2002) argue that the improving image of the industry seems to be a magnetic force. A staff environment that is usually young, communicative and resourceful may suit many people. Thus despite poor working conditions in the industry, satisfaction and attractiveness motivate individuals to take up jobs in the industry.

In respect of human capital requirements, the hospitality workforce has been labeled by many as semi 'skilled' or 'unskilled' / 'non-skilled' (Wood, 1992; Shaw \& Williams, 2002; Lucas, 2004; Walmsley, 2004). The notion of 'skilled' or 'unskilled' jobs have been discussed by Burns (1997) who argues that: "Iabelling the majority of the workforce as 'semi-skilled' or 'unskilled' (as in the case of hospitality) creates something of a myth that diminishes workers' contribution to customer satisfaction and the intended corollary of business profitability" (p.239). Soft skills such as being 
amicable, responsible, flexible etc. could be called 'interpersonal skills' and are not perceived as 'skills' per se. This suits employers who classify the majority of their workforce as 'unskilled'. Furthermore, Burns (1997) argues that tourism 'skills' are not only rooted historically in the occupational classification as being low but are used as a justification for low wages. This issue has been raised in other studies and many report that the perceptions of 'unskilled' labour became a stereotypical model and such views are rather out of date and unjustifiable (Choy, 1995; Baum, 1996, 2007; Burns, 1997; Nickson, Warhurst, \& Dutton, 2005; Warhurst \& Nickson, 2007). Such understanding of hospitality work "neglects dimensions of service and communication within hospitality work, arguably today the critical component at the international level" (Baum 1996:207). Thus soft and social attributes including the ability to understand guests' expectations and the ability to communicate in a verbal and non verbal way have been neglected. It has been reported (Shaw \& Williams 2002) that the sector concentrates on 'technical' aspects of skills and disregards interpersonal skills, including the knowledge of foreign languages. Such a perception of tourism and hospitality employment is not only inaccurate but also creates a negative image of the industry. A study by Nickson et al (2005) conducted in Glasgow in the retail and hospitality industries confirm the importance of 'soft skills'. They revealed that employers look for skills which encompass the social, interpersonal and aesthetic skills that are related to appearance. Similarly, personality, attitude and character were found important for employers in a study on labour turnover (Rowley \& Purcell, 2001). This is confirmed by Hai-yan and Baum (2006) who explored staff working in front office in four and five star hotels in the major cities in China. When asked about skills requirement for work in front office, oral communication skills as well as professional and ethical standards were rated as the most important skills. Other vital skills were team working, leadership qualities, customer care and interpersonal skills.

The ranking of hospitality jobs as 'unskilled' has important implications for migrant workers. Such perceptions of skills or semi - skills offer an easy access to hospitality jobs and as pointed out by Riley, Ladkin and Szivas (2002), the industry accommodates those with a great variety of skills, with low skills level or with non-relevant skills (p. 23). The downside of such perceptions is that it is related to the poor image of the sector and consequently to low pay and low status.

Finally, in terms of migrant workers' experiences, seasonality is a factor to consider. Seasonality is perceived as a major challenge for the industry (Hinch \& Jackson, 2000; Asworth \& Thomas, 1999; Krakover, 2000a; 2000b; Lee-Ross, 1999; Duvall, 2004; Jolliffe \& Farnsworth, 2003; Lundtrop, Rassing, \& Wanhill, 1999). It creates a wide variety of complications such as huge turnover and ebbs and flows of temporary labour. Further, it influences industry employment, leading to seasonal 
employment, underemployment and unemployment (Jolliffe \& Farnsworth, 2003). Thus during the slower season, staff are unemployed or underutilised. Shaw and Williams (2002:175) state that: "Most localities have a single peak season, flanked by shoulder seasons. The out of season period may be one of reduced activity or total closure". Hinch and Jackson (2000) point out that the tourism authorities spend considerable time, money and effort modifying these patterns through particular strategies like creating all season destinations or extending the shoulder seasons to tackle seasonality. However, from the perspective of migrant workers, seasonality may be an attractive feature of the industry. Empirical studies suggest that seasonality may not be considered problematic by some businesses (Duvall, 2004) or employees who accept working just a part of the year (Lundtrop et al, 1999; Andriotis \& Vaughan, 2004; Lee-Ross, 1999; Lundmark, 2006). Certainly it does create notions of temporariness which in turn has an impact on the migrant experience.

To summarise, the studies discussed serve as a background to understanding why Polish migrants have been attracted to the hospitality sector. The key features of the industry set the context for this study of migrants' experiences as the occupational features of the hospitality sector provide a framework for certain conditions and employer needs that have a significant influence on employee experience.

\section{Method}

The study adopts a pragmatic theoretical perspective, defined as a viewpoint in which researchers use all approaches available to understand the research problem (Creswell, 2009). The research uses both qualitative and quantitative methods, adopting an approach developed by Miles and Huberman (1994) who argue that one way in which qualitative and quantitative methods can be linked is through exploratory fieldwork which leads to the development of a quantitative instrument such as a questionnaire and then the questionnaire's findings can be deepened (or tested) with the next round of qualitative data.

Following this argument, this research began with exploratory fieldwork, using netnography (Kozinets, 2002; Langer \& Bekham, 2005), followed by a small number of interviews conducted with past and present hospitality workers in Bournemouth, an established Seaside holiday destination in the UK, leading to the development of a quantitative instrument. An online survey was designed and distributed on online fora across the UK and social networking sites. The questionnaire's findings 
were further deepened by the next round of qualitative data obtained again through netnography. In this way, each method was informed by the findings of the former.

\subsection{Research Stages}

In the first phase, a netnographic study was carried out in order to gain general views of the experiences in the hospitality sector among Polish employees. This was carried out between December 2006 and April 2007. The use of the Internet as a research tool has been well documented (Hewson, Yule, Laurent \& Vogel, 2003). The principal reason for choosing netnography and a web based questionnaire is the high Internet usage among Poles, both at home and abroad. Poles are the highest registered groups of Skype users after the Americans and Chinese (Bendyk, 2006), and are also the fourth greatest of all language groups involved in blogging (Trammel, Tarkowski, Hofmokl, \& Sapp, 2006). In addition, the most popular social networking site in Poland (nasza-klasa.pl, [our class]) reached 11 million registered users in 2008 which again confirms the high Internet usage among Poles. The traffic on Polish websites from the users in the UK since the 2004 EU Enlargement has increased twelve times (Bendyk, 2006). Technological literacy and Internet usage have an important relationship with migration as the Internet becomes the public sphere where new and established migrants exchange advice and resources about a destination, weather, dominant industries, job vacancies, skills required and housing. A detailed overview of using netnography as a method to analyse hospitality workforce experiences is discussed elsewhere (Janta \& Ladkin, 2009).

The emerging themes from the initial netnography were explored in six interviews, which formed the second phase of the research. These were conducted in October 2007 and each took between 35-100 minutes. The interviews were conducted using a semi-structured interview guide following interview etiquette and using Berg's (2004:110) 'commandments of interviewing' (Jenkins 2001; Denscombe, 2008; Berg, 2004). Thus, question order, content and style as well as the researcher's appearance, attitude and choice of comfortable places were considered. All the interviews were recorded to improve the accuracy of the data and notes were taken to support the recordings.

The data from netnography and the interviews served as a basis for the development of a questionnaire survey, phase three. The questionnaire was piloted in December 2007 and after revisions, the main survey was distributed online. Messages with a hyperlink to the online survey were posted on 45 regional and general fora across the UK and on two large social networking sites: Facebook.com and Nasza-klasa.pl (Our class). The former is the largest international social site with over 500 million users (Facebook Statistics, 2010). The latter is the largest and most popular social 
networking platform in Poland (on social networking sites see: Boyd \& Ellison, 2008; Ellison, Steinfield, \& Lampe, 2007; Hargittai, 2008). New threads were started on the discussion fora containing a question in a title and a message asking for help in the research by filling the survey. The messages contained a hyperlink to the external site. A total of 420 questionnaires were returned, of which 315 were complete. Only the completed questionnaires were used for analysis.

The final phase returned to the netnographic and interview data to assist with interpretation and analysis of the questionnaire data.

\subsection{Sampling and data collection}

Data were collected through questionnaires, netnography and in-depth interviews, beginning with netnography. Sampling issues are not discussed in detail in netnography, and as Kozinets (2002) points out, sampling includes "carefully chosen message threads" (p.12) and is similar to purposive sampling. Further, according to Kozinets, the sample does not have to be representative (2002:12).

A survey instrument was used to collect the data across the country. Given that the Polish hospitality workforce represents 'a hard to reach' population, the purposive sampling strategy was employed to access respondents. In the absence of reliable population frames for Polish hospitality workers, the sample used in this research is necessarily purposive. The disadvantage of using purposive sampling is that it is not reflective of the total population, nevertheless, such non-probability sampling is common for Internet surveys (Schonlau, Fricker, \& Elliott, 2002; Sue \& Ritter, 2007). The questionnaire was distributed on the Internet fora used by Polish migrants as well as social networking sites between February and April 2008. There were two reminders posted and 'thank you' notes to increase response rates.

\subsection{Data analysis}

For the qualitative methods, both the netnography and interview data were analysed using thematic analysis, defined as "a method for identifying, analysing and reporting patterns (themes) within data" (Braun \& Clarke, 2006:79). It includes searching for themes across a data set to find repeated patterns of meaning and a constant moving back and forward between the entire data set. With regard to the survey findings from open-ended questions and respondents' comments the same method was used; the data from each question were copied, theme analysed and grouped. The findings presented here are organised by these identified themes, with examples of original quotes from the respondents translated into English. 
For the quantitative survey data, the Statistical Package for Social Sciences (SPSS) V16 was used. The first stage of data analysis used descriptive statistics conducted on all the variables.

As a point of clarification, in the discussion of the findings, qualitative comments from the questionnaires are shown by the questionnaire respondent number, data from the netnography lists the Internet site, and the respondents names are given where the data derives from the face to face interviews.

\subsection{Profile of sample}

The sample for the questionnaire consisted of 315 individuals, those who were currently working within the hospitality industry $(\mathrm{N}=173)$ and those who had previously worked in the sector but had since left $(\mathrm{N}=142)$. The sample is consistent with past research and government figures, as in this study, nearly three quarters of the respondents were female $(\mathrm{N}=225)$. A large proportion of women are evident in the UK hospitality sector (People $\left.1^{\text {st }}, 2006\right)$. Regarding age, this ranged from 18 to 55 years old. The vast majority of the respondents were under 30 with a mean age of 26 . The level of education was found to be exceptionally high; with nearly half of the respondents having either a Bachelor or Master's degree $(\mathrm{N}=147)$ and another group studying $(\mathrm{N}=58)$. The educational level and the age of respondents correspond with past studies on foreign workers in the UK hospitality sector (Baum et al 2007; Devine et al 2007a, 2007b). Regarding location, England is a dominant location for migrants. With regard to job positions, it is evident from this research that migrants enter the hospitality sector by starting as, for example, housekeepers, kitchen porters and waiters/ waitresses.

\section{Results and Discussion}

\subsection{Reasons for entering the sector}

The respondents were asked to rate on a 5-point Likert scale their degree of agreement or disagreement with 11 statements, giving possible motives for taking a job in the hospitality sector in the UK. These statements were extracted from the literature on tourism mobility (Szivas \& Riley, 1999; Szivas et al, 2003; Vaugeois \& Rollins, 2007) with others added from both the netnography and interviews. The responses on a scale such as 'strongly agree' and 'agree' were collapsed into 'agree' responses. The initial analysis revealed that at the top of the list, $82 \%$ of respondents choose to work in hospitality because they wanted to use foreign languages. Equally important for the respondent was that they could start working as soon as possible, with $81 \%$ agreeing that this was 
important to them. Further, $60 \%$ wanted to gain some work experience and another $51 \%$ agreed that receiving benefits such as tips or meals was an important motive.

In order to further examine the importance of every statement the possible motives were ranked by their mean scores. When interpreting the scores, lower means indicates disagreement while higher scores imply agreement (strongly agree $=5$, strongly disagree $=1$ ). The means and standard deviations for the 11 statements are shown in Table 1.

The statements, means and standard deviations are illustrated in Table 1.

Table.1. Means and Standard Deviation for the statement list

\begin{tabular}{lcc}
\hline Statement & Mean & SD \\
\hline I wanted to use foreign languages & 4.23 & 1.14 \\
I could start as soon as possible & 4.12 & 1.21 \\
I wanted to gain work experience & 3.40 & 1.39 \\
I receive other benefits (food, tips etc) & 3.18 & 1.44 \\
I heard it was easy to find a job in this sector & 3.01 & 1.34 \\
I needed a job which did not require any particular qualification & 2.91 & 1.42 \\
I needed a temporary job & 2.81 & 1.62 \\
I could not find a job elsewhere & 2.61 & 1.41 \\
I needed a summer job & 2.30 & 1.66 \\
I did not know how to look for a job & 2.23 & 1.29 \\
I have qualifications in hospitality & 1.66 & 1.34 \\
\hline
\end{tabular}

This analysis illustrates some positive attitudes towards taking up jobs in the sector. The statement with the strongest agreement was: 'I wanted to use foreign languages'. The choice of this statement suggests that the interpersonal contacts and interactions with other nationalities are seen by the respondents as attractive. The primary aim of the migrants may have been to improve their English and this type of work does afford some opportunity in this regard. The second statement with the strongest support was: 'I could start working as soon as possible'. This suggests that migrants wanted to enter the labour market at the earliest opportunity and it supports the argument that Poles may not be well prepared in job searching abroad, or they may be students looking for summer employment. Although migrants have a high level of educational attainment (Anderson et al. 2006; Devine et al. 2007a, 2007b; Baum et al. 2007), they are not willing or able due to financial 
imperatives to spend time searching for jobs. Instead, they enter the labour market on the first available occasion. This supports previous study conducted in Hungary (Szivas \& Riley, 1999) who revealed that tourism may not be the first choice of industry but it is easily obtained. Set in this context, this could represent a constrained choice rather than an active desire to work in the tourism industry. The third strongest statement indicates the positive image of hospitality employment: 'I wanted to gain some work experience' indicates that getting some initial experience in the British labour market is important as it may increase the chances of finding another job. Again, this may be a result of constrained choice rather than an active desire to work in tourism. This is supported by other studies. For example, Aycan and Berry (1996), in a study conducted in Canada revealed that a lack of Canadian experience among Turkish migrants was a disadvantage on the labour market on arrival. The fourth statement points to the industry's benefits again: 'I receive other benefits (food, tips etc)'.

The first and third statements suggest that hospitality work will allow using certain skills, further it suggests the value of interpersonal contact in this working environment. These could be viewed as positive reason for entering the sector. The statement with the lowest agreement was: 'I have qualifications in tourism' indicating that many of the respondents have been trained in other areas.

A further issue factor to explore in this context is that the reasons for entering the sector may vary by age, or by gender. Upon further investigation, exploring the sample by age indicates that starting the job immediately was more important for the older respondents. More specifically, those above 29 years of old scored a mean of 4.15 and standard deviation of 1.294 . For the youngest respondents, those below 20 years old, the use of foreign languages was the most important factor (a mean of 4.43 and standard deviation of .996).

Similarly, those below 20 years old were also looking for a temporary job in contrast to older respondents (a mean of 3.28 and 1.545). This indicates possible distinct groups of people, those simply looking to gain work experience or as temporary work for summer, against those who view the migration as a longer term commitment.

Furthermore, some differences were found between male and female respondents. While for women 'using foreign languages' was the most important factor, (mean of 4.32 and 1.054). For males the mean is 4.01 with a standard deviation of 1.311. However, for males 'getting a job as soon as possible' was slightly more important than languages, with a mean and standard deviation of 4.07 and 1.305 as opposed to 4.01 and 1.311 respectively. Furthermore, for males, receiving 'other 
benefits' (mean of 3.20, STD 1.46 was more popular than gaining work experience. (Mean of 3.16, STD 1.453).

The pattern that emerges is of males focusing on economic gains rather than skill development. We can only speculate on the reason for this, but it may be that male migrants are under pressure to earn income abroad that may be used to support families back in Poland.

In general, some of the reasons for entering the sector are positive; migrants want to use foreign languages, gain work experience and receive benefits that the industry provides. However, this is open to interpretation. For example, 'I could start work as soon as possible', 'I heard it was easy to find a job in this sector' and 'I needed a job which did not require any particular qualification' could equally be interpreted as a constrained choice. It may be that the migrants urgently needed income and it was all that was open to them, it represents an easy job to find because of poor working conditions, and the lack of specific qualifications required reflects the low skilled nature of the work. To discover if these were issues that affected the choice and whether or not they were viewed negatively or positively requires further investigation.

Further analysis reveals that migrants' aspirations may change over time. Whilst many initially came to the UK seeking temporary work, many have stayed longer. The following quote represents the experience of many.

"I came (to the UK) 3 years ago to a language school. It was supposed to be school, work and accommodation, and it was supposed to last 3 months (laugh)... It was arranged in Poland through a recruitment agency." (Asia, hotel receptionist)

For some, plans to stay longer conflicted with continuing to work in hotels, for example. When Asia was asked about her plans she stated:

"I have a dilemma. I don't know whether I should go home or stay here. If I stay in England, I know for sure that I don't want to work in the hotel, I am 100 percent sure. I would like to either look for an office job or work in my field. I graduated from the Agricultural Academy in Szczecin. (...) I think I don't like serving customers; it annoys me that you have to be nice every day, and unfortunately not everyone can do these things. So I could maybe move to another department, some back office, but then what? If I get there, how much will I earn? Maybe 18,000E annually? For the rest of my life... but if you settle down in England, to buy a house or something, you cannot work in a hotel, for sure. "

Similar view was expressed by, Magda, a hotel worker: 
"I have been here for too long, this is my fourth year in this hotel. I do the same thing all the time. I would like to do something different, something more ambitious, something that requires less customer contact. (...) I don't have plans, but my dream would be to have a job related to my studies, something to do with fabrics, medicine or chemistry or maybe a laboratory worker. I would like it."

Alternatively, some migrants have found their experience in the sector to be positive, and they have stayed longer to continue working in hospitality. This can be illustrated in the case of an assistant manager, Marek, who talked about his arrival:

"I came here for one year. We just wanted to save some money, and nothing else, no career, nothing like that. But later on, I thought that I was already here in this restaurant, I can stay one year longer, I will try to became a wine waiter. And then I decided, I will try even more, and I succeed; I had a bit of luck and I took the risk."

Given the different reasons for entering the sector, it is reasonable to assume that the migrants' subsequent experiences are shaped by these needs and are subject to be influenced over time. How these reasons for entering the sector relate to the migrants' experiences is the second area for investigation.

\subsection{Experiences of working in the UK hospitality sector}

Migrants' comments can be divided into two broad areas; those relating to the positive experiences of working in the sector, and those negative views concerning working conditions and their experiences. Each is discussed in turn and where there is ambiguity in this differentiation it is elaborated on within each section.

\subsubsection{A good first job}

Several respondents stated in the questionnaires that jobs in the hospitality sector are a good starting point for working in the UK. Illustrative comments include:

"I think that it is a good job at the beginning of the stay in the UK, because it gives a contact with people on a daily basis which helps to improve the language skills, meeting other cultures," mentalities...

(Respondent 260) 
"It is 'a school of life' for those who do their first steps in the UK. After the initial shock you get over it and you realise your own abilities and merits." (Respondent 74)

"I think that working in hospitality is very good for the beginning, especially if one doesn't speak good English. But it is worth finding a hotel, restaurant, bar or another place where one can find additional bonuses (for example accommodation, meals, tips) and where there is a nice atmosphere. Those who want to improve their English, it is important not to speak Polish at work. "(Respondent 203)

"An excellent experience but for short term. "(Respondent 82)

For many, hospitality work is their first experience of working in the UK. This type of employment gives migrants a chance to improve language skills and learn about their own merits. It is considered a training ground for those who have just arrived in the UK and have to learn quickly about the new environment as well as themselves. According to Lucas and Mansfield (2008), hospitality employment has certain characteristics that enable migrants relatively easily to find work. As the employment opportunities available to newly arrived migrants tend to be confined to unskilled, low paid occupations; hospitality work represents one element of constrained choice. Employment is seen by many as a first stop, the experience is valued as temporary only; therefore, the comments must be viewed in this context. This initial phase helps migrants to become more independent as they settle into life in the UK, and offers a 'breathing space', for example, it gives

"Time to organise necessary documents." (Respondent 50)

"Time to get to know the culture and local language." (Respondent 173)

"It gave me the chance to survive the first year and to find a better job." (Respondent 10)

As a first step to working in the UK, hospitality employment therefore can be viewed as a positive part of the migrants' experiences. The temporary nature of this first step will of course influence the migrants' feelings towards this initial employment.

\subsubsection{People and atmosphere}

The research reveals that Poles see the opportunity to meet other co-nationals, hosts, non Europeans and non-white people from all over the world as an advantage. The following comments from the questionnaire data are representative of the issues raised by many; 
"I have met lots of wonderful people from Poland and other countries (also non-European). " (Respondent 255)

"(It is) an opportunity to meet interesting people (and) a partner." (Respondent 82)

"Superb atmosphere (for the first time I have worked for an African woman and with people from other continents and countries). "(Respondent 101)

"Through contacts at work I met lots of people including my next employer from a marketing company." (Respondent 173)

This type of experience was supported by the interview data, for example, Marek, and assistant manager reveals:

"In this hotel, for sure, the atmosphere plays an important role; we go out whether it is someone's birthday, a football match or a football match on TV. This is like being at school or at university. "(Marek)

And;

"I know a Philippine boy very well. He invited me for a trip to London once; he showed me the Philippine cuisine. People do tell many stories, for example, how they spend Christmas in different countries. (...)" (Marek)

Again in relation to the diversity of the workforce;

"It was a place like a melting pot. Diversity in restaurants is so wide; it is a great place for communication with people coming from all over the world. "

(Jakub, ex restaurant worker)

These examples illustrate that hospitality employment can provide a positive working experience with opportunities for self development and gaining life experiences that go beyond the workplace. It was previously stated that hospitality employees derive most satisfaction from social relationships (Lucas, 2004; Riley et al. 1998) and it is evident that migrants enjoy working in a multicultural environment, although the opposite was found in another study (see Wright \& Pollert, 2006), where such interactions were a source of problems for foreign employees. Although the 'mixed bag' of 
cultures largely results from the concentration of low paid migrant workers in the hospitality sector, this is not necessarily seen as a disadvantage for the migrants. Evidence from other industries where migrant workers dominate indicates dissatisfaction if migrants have no contact with the host population, but spend all their time with other co-nationals (MacKenzie \& Forde, 2009). The nature of hospitality work indicates means that whereas back of house operations may be dominated by migrant workers, those employed in the front of house occupations have contact with the local population. This in turn affects their working experiences.

\subsubsection{Flexibility in the sector}

Despite the often negative reports on working hours and shift work, in this research, the sector's flexibility was highlighted as a positive element; the flexible working hours helped the respondents to do other things simultaneously:

"(It gave me) a relatively good and quick start in the UK, (and) quick money covering basic needs. Work in gastronomy is a good base for looking further job, i.e. in someone's field (days off during the week, a chance to swap rota with other co-workers etc. It favours when going to a job agency and job interviews. " (Respondent 279)

In this context, the sector's flexibility is a merit as it gives an opportunity to look for a job outside the sector. Flexibility helps to keep a balance between work and personal life; being able to swap shifts with colleagues allowed migrants going for a job interview, studying or even going back to Poland to continue studying:

"Most importantly (it gave me) flexible working hours what was salient because at the same time I was studying full-time." (Respondent 126)

"Being able to fit work with studies is good." (Respondent 276)

"In my case (it was) flexible working hours, also many unpaid holidays, which I have needed for studying in Poland." (Respondent 212)

"It's not easy to say that I have succeeded ;) but I am pleased at having been here for few months now. (...) I am studying full-time doing a postgraduate course related to my profession which is translations (I graduated from English studies in Poland). Apart from that, I am working in a nice restaurant as a supervisor (I started as a waitress) (...). Generally I 
can't complain and trying to stay positive :) I hope that one day I will be able to work in my profession, for now, I am improving my accent and the language. "

(gazeta.pl, 01.01.07)

Therefore, the message seems to be that many of the migrants make use of the flexibility of the work to their own advantage. This is largely a reflection of the age and life stage of the migrants who are not looking for regular working hours, or are trying to balance the demands of family life. The flexible working hours benefits the employers who are often looking at profit maximisation and low cost labour, and this is unlikely to change given the nature of the hospitality industry. The fact that the migrants see these conditions as beneficial is a clear bonus for employers. Not offering alternative contracts can be viewed as an management strategy on the part of employers (MacKenzie \& Forde, 2009).

\subsubsection{Income}

In this research, several respondents mentioned the financial benefits of working in the sector. Illustrative quotes from the questionnaire data are;

"It helped me to pay for school and living expenses." (Respondent 244)

"Sometimes good tips." (Respondent 266)

"Savings that let me go back quickly to Poland. "(Respondent 193)

“Cash for visiting England in my spare time. "(Respondent 272)

According to one interviewee,

"Having even the lowest wages in the hotel, more less 180 f per week in your hand, you are still able to eat, go out and maybe save some money." (Marek)

The migrants explained that the money helped them to pay for education, buy tickets to Poland or provide extra cash for sightseeing in England. Comments also concerned extra benefits from working in the hospitality industry such as tips. This element of receiving extra benefits was seen by migrants as one of the top reasons for taking up employment.

The benefits are illustrated by Artur;

"Later on, I started working as a hall porter and room service asisstant so I was serving food to the guests' rooms. I was working extra hours in this hotel, so at some point I was working 
70/ 80 hours per week. I had a period of time where I could save f1000. The tips from delivering suitcases to the rooms were so high that I could earn a second salary from them. "

Therefore, the money was a step towards self-reliance in the UK and provided income for a range of different activities. Again, this has to be related to the motivations of the migrants for taking employment in the sector. As with students, migrants appear to have their own set of motivations and expectations for seeking work, including what they hope to gain from it and the time frame they expect to stay (Lucas \& Mansfield, 2008). In our sample, many of the migrants were students, and the majority of the sample expected to stay in the UK a short time. If the primary motivation was to earn money then hospitality with the added bonus of tips was seen as a positive factor. Clearly a highly paid job would have the same outcome, but this type of work is not easily available to migrant workers.

\subsubsection{Exhaustive long hours' culture}

The hospitality sector is plagued by a culture of long hours, often at all occupational levels but specifically in the lower skilled jobs. For many of the respondents the nature of hospitality work is seen as exhausting. Many of the complaints listed that jobs are 'hard', 'very hard' and 'too hard':

"Horrible, hard work - typical work 'for the start'." (Respondent 222)

"Hard work mainly at weekends, changing working times." (Respondent 105)

"Work is usually hard. All day long on foot + getting up early or going to bed late. “(Respondent 34)

This is confirmed by Marek during his interview:

"When I worked in the restaurant, I was sleeping all day long; I would come back from the restaurant, go to bed, get up, come back in the evening and go to bed again. We went out for the very first time after 8 months of working here. (..)" (Marek)

Such features like tiredness from long hours, back pain and work overload are related to health and safety issues. Physical tiredness is revealed in the following expressions such as: 'not being able to move', wanting to 'swear it all off', 'crying from tiredness', 'crying from pain' and 'dead on feet'. Performing this kind of physical work was also compared to a hard working character from Polish literature, a modernist period female athlete (Silaczka) written by Stefan Żeromski in 1891 (see Żeromski, 1973). 
"Very hard work, particularly as the hotel is not a small one. I think of myself as a hard working person, but I now recall that sometimes I could feel that it was beyond my strengths, and (I recall) that sometimes I cried from the pain, from tiredness, but it seems like I am 'Siłaczka' (female athlete), I like to go all out. "(Respondent 255)

Other health and safety concerns of respondents included back pain:

"Before starting working as a Kitchen Porter, I haven't known that the back can hurt so much; I am $193 \mathrm{~cm}$ in height. "(Respondent 153)

Similar problems related to pain are reported elsewhere (Wright \& Pollert 2006). Further, working time and its uncertainty is seen as a drawback:

"Rota is written on the last days of the week - you can never plan anything because they might need you and call you (zero free weekends!!!)." (Respondent 34)

"Changing working times depending on the volume of customers in the hotel." (Respondent 15)

As stated by one of the respondents, the volume of customers influences employees' working hours, and a further disadvantage is that employees are always needed at weekends. One of the respondents describes her working week as follows:

"It is pleasant to work from Sunday to Thursday, but Friday and Saturday are killing me off, and I feel like swearing it off, but this is the only drawback. "(Respondent 257)

Therefore, as the working week progresses it gets harder and more tiring for an employee.

The above quotes illustrate some of the difficult experiences brought on by working in the hospitality sector. The work is physically demanding and this can lead to a stressful employment experience. The long hours are often made worse by shift patterns and spontaneous changes in demand whereby employees may be asked to work longer if the need arises. Furthermore, as with many low paid jobs, opportunities for overtime or increasing the number of hours are a way to earn more money, and workers may voluntarily take on additional work. Evidence from previous research (MacKenzie \& Forde, 2009) indicates that for many UK migrants, the long hours were regarded as favourable as it provided the opportunity to maximize earnings through overtime. The 
difficulty in maintaining a decent work-life balance in the sector is widely recognised (Karatepe \& Uludog 2007; Wong \& Ko 2009).

\subsubsection{Experience as a Kitchen Porter}

Experiences of certain jobs in hospitality are widely discussed on the Internet fora. Discussions related to jobs for Kitchen Porters are one of the popular themes. Interviewees also had strong views on certain job positions and perceptions of KP and waiters' roles.

Working as a Kitchen Porter (KP) carries a particular meaning and social stigma (Saunders, 1981). Discussions involving Kitchen Porters or references to such work appear frequently on the Internet fora. The KP post has become a symbol of the most unpleasant job, being often the first job available there. Poles have labelled this as 'working at the sink' (na zmywaku). One of the topics launched on gazeta.pl provoked a discussion under the title: Why are qualified Poles washing pots in the UK? (02.08.06). The user's opinion is that highly qualified migrants coming from other countries such as Germany, France, America, Brazil and India, in contrast to Poles, take up jobs according to their qualifications.

Discussing the thread under the title: 'are you planning to go back to Poland?' the KP job appears as the job on the very bottom of the employment level:

"Among my friends nobody works 'at the sink', each does what he/she likes" (gazeta.pl, 14.01.2007)

When examining the situation of the labour market between those who are about to arrive and those who have been in the UK under the thread: 'don't come! No work here!' the lack of jobs is discussed using a KP jobs position in the following way:

"Only those who have worked in the UK before and those who speak English well those will find a job - even such as 'on the sink' - this is what it looks like now!'”(gazeta.pl, 30.01.2007) Despite suggestions that not all hospitality jobs have a bad image, a job that includes washing dishes in the kitchen is the one that has a stigma attached. Jobs found in hotels and other hospitality places, especially those in the kitchen are perceived as temporary and those who discuss them have other ambitions: 
"if you don't respect yourself, don't expect others to respect you. One can wash pots or 'run with a mop' but only as long as it takes finding a job that is appropriate for you". (gazeta.pl, 19.01.07)

These experiences of working in the kitchen 'at the sink' are very common among Poles. Jobs for KPs are viewed as low status and they are jobs that anyone can get. This is expressed by an interviewee, Artur, in the following way:

"Somehow I survived my first day at work there and then I started thinking; damn it, what have I done? I worked in a bank a week ago and I came here, I got a KP position... But I can't give it up because if I do, I will get into troubles."

"Working as a KP was below my qualifications; it was a job abusing my qualifications (laugh)... but I realised that I prefer a downgrading job for decent money than a good job for downgrading money, which I had back in Poland."

The perception of such work as downgrading and depressing was reported by Saunders (1981) and the respondents perceive it in a similar way. There is unhappiness expressed on the mismatch between qualifications and job performed but also the awareness of the reasons for taking up work in hospitality. Loss of status is not uncommon for those moving to a new country of settlement (Berry, 1997) which results in stress.

\subsubsection{Low Pay}

Possibly one of the most widely discussed features of hospitality employment is that of low pay, or rather pay at minimum wage rates. As a key feature of hospitality work, it is not surprising that wages and problems with pay were criticized by employees.

"For such hard work, the wages were poor and our working hours were lowered." (Respondent 232)

"Low wages in most of the departments are one of the downsides. "(Respondent 208)

This is echoed by Jakub:

"When you work in a restaurant, the money is not great. I don't allow myself expensive trips or exotic holidays. What makes me happy is meeting up with Poles, spending time together." (Jakub) 
The problem raised by the respondents includes irregular wages that depend on how busy a workplace is. For example,

"Your wages depend on the level of business, so if the business goes badly, you earn less!!" (Respondent 34)

Receiving a bonus for so called 'outstanding attitude' was mentioned by a respondent who felt humiliated:

"Downgrading bonuses, (I got $£ 10$ bonus for outstanding attitude - hotel NAME REMOVED. I would rather not get anything." (Respondent 129)

Problems related to wages in hospitality appear also on the Internet fora in the form of a warning: $A$ warning against a hotel (ang.pl, 06.06.2007). A female user offers some more details on what she has experienced in a UK hotel and warns potential Polish jobseekers against getting a job there:

"The summer is approaching and many people will surely go to England for work. I would like to warn those people against a hotel in (NAME REMOVED). The name of this hotel is (IN CAPITAL LETTERS) and it is located by the seaside next to (LOCATION REMOVED). The hotel is run by a married couple. They are both really mean and unfair. They pay per day, not per hour. It is $£ 25$ per day and you have to stay there literally all day long. (...) He is not fair. He says one thing and then doesn't keep his word. He is not willing to employ legally. (...) My brother worked there for two days and that was enough. After the two days he gave up and had problems to get his money."

Similar problems were also identified by on a different Internet fora:

“(..) wages....it all depends on a hotel, even among NAME REMOVED hotels it varies: each hotel may have a different owner and have a different policy. The owner of my hotel is, unfortunately, a (NATIONALITY REMOVED woman, who is stingy and 'pull in' others (A HOSTILE NAME FOR CERTAIN NATIONALITIES REMOVED) and pays them ridiculous money as for them it is like 'America'. (...)"

(monikauk, 23.11.06, gazeta.pl)

Remuneration is important in any job, and studies indicated that it affects motivation and overall satisfaction (Lam, Zhang, \& Baum, 2001), and may lead to the decision to leave (Walmsley 2004; 
Dermody, Young \& Taylor, 2004). Wages in hospitality are assessed as a source of dissatisfaction, and for many, overtime becomes the norm to increase income.

As previously discussed, MacKenzie and Forde (2009) found in their study of migrant workers in the UK that despite the low pay, the long hours of work offset these and gave opportunities to earn more money. On the basis that wages were only paid at the minimum wage, the ability to work long hours was presented as an opportunity to offset this. Overtime with higher pay was considered an attractive option.

\subsubsection{Discrimination}

As identified by Lucan and Mansfield (2008), the hospitality workforce is characterised by certain types of workers who are associated with being marginalised within secondary labour markets. Despite the many examples of good practice and legislation to protect workers, inevitably evidence of unequal treatment was found in the hospitality sector. Baum (2006) observes that discrimination either implicit or explicit, is unacceptable in the industry, however there are many reported incidents that clearly show malpractice does occur. Discrimination and racism were discussed by the migrants when expressing views on working in the sector. Several respondents gave examples, often comparing themselves to local staff:

"Poles working in hotels and restaurants are required to do 'miracles' in a quick time so, after work, one is all but dead on their feet, and is not even able to move, while the locals work slowly and burden the foreigners with their duties." (Respondent 61)

"Poles are appreciated at work; however, they are not rewarded as much as their English (mother tongue) colleagues are." (Respondent 244)

"First, I worked in a hotel (it was a job with 'study and work'), then (I worked) in a bar, where I found the job by myself and in both case there was exploitation, Poles were treated worse than the English were." (Respondent 233)

These examples demonstrate that in some instances the Poles found themselves treated worse than their British co-workers; are reprimanded more frequently, or even paid less than local staff. It seems that the respondents believe that they are expected to work harder than others. Wright and Pollert (2006) reported similar issues related to discrimination, racial abuse by restaurant customers 
and bullying from the staff. In this study, mistreatment from customers has not been reported, however, management was criticised for racial abuse and exploitation. Evidence of discrimination is part of the wider issues concerning the employment of marginalized groups often on temporary contracts. To a certain extent the system relies on a through flow of fresh employees who may have little intention to say. Evidence suggest that workers become more demanding over time as they become aware of their entitlements and alternative opportunities (MacKenzie \& Forde, 2009: 150). However, the transient workforce makes malpractice easier to thrive.

\subsubsection{Management Attitude and Behaviour}

Comments from the workers demonstrate that in some instances, management were criticised for abusing their positions:

"If you ever experienced being put down/lack of respect from co-workers or an employer, you don't have to be afraid but face it (from the beginning). If not, then you have to leave, because work in this sector is easy to find. This is what I did, a London hotel was a nightmare and, in Reading, I assigned my place from the start. "(Respondent 201)

"It is not worth being humiliated for the sake of a few pounds; if an employer doesn't respect an employee, it is not worth staying in such a place." (Respondent 203)

"Our team leader was a (REMOVED) - alcoholic, and often came drunk to work (which means he was coming sober sometimes); because of that, we did more work and, in fact, we held everything together." (Respondent 93)

The complaints towards management including drinking at work or not showing enough respect to workers point to illegal practices at work. Disrespectful treatment of workers and problems with drinking among managerial staff were reported by Poulston (2008) in a study in New Zealand. The lack of appreciation from employers was also mentioned by a respondent:

"The employer did not appreciate our work, and this is sad because you need some motivation, even when working as a housekeeper :) "(Respondent 106)

As assessed by a respondent, working as a housekeeper also requires motivation that should be encouraged by the employer. Being appreciated, welcomed and cared for the employers was identified by Yong and Lundberg (1996) as important to reduce staff turnover that mostly occurs within the first few months. 
Finally, the qualifications of management were also a subject of disappointment:

"Generally, those working in hospitality haven't got a clue what they do, their qualifications are embarrassingly low. "(Respondent 47)

"My position in the hotel didn't reflect my qualifications. Those working in managerial positions had no qualifications, while very often those working as waiters/waitresses from different nations had a master's degree. "(Respondent 170)

In contrast to immigrants themselves, those in managerial posts have low or no qualifications. As reported elsewhere (Anderson, et al. 2006; Devine, et al 2007a, 2007b; Home Office, 2008), the level of schooling of immigrants themselves is very high, which may result in disappointment and disbelief that those who manage them may not have any formal qualifications. This may also impact on their well-being.

\section{Conclusion}

This research contributes to the literature on migrant employment experiences in several ways. It provides an insight into migrants' experiences at work, and consequently their views on working conditions, an area that has received little attention despite the growing number of studies on migrant workers. Furthermore, previous research has focused on agency staff (Evans, Wills, Datta, Herbert, Mcllwaine \& May, 2007) and irregular workers (Wright \& Pollert 2006; Wright 2007) as opposed to European Union migrants, which is the primary focus here. The research also complements studies on work-life balance, workload and the sector's $24 / 7 / 365$ culture by providing insights into the nature of hospitality employment, and its positive and negative implications for migrant workers. It further adds to the research on problems at work that migrants face in the hospitality sector (Wright \& Pollert, 2006; Evans et al 2007), identifying issues surrounding pay, management behaviour and discrimination. It also provides an understanding of employees' reasons for entering the hospitality sector (Szivas \& Riley 1999; Szivas et al. 2003; Vaugeois \& Rollins, 2007). Finally, it builds on previous work by Baum et al (2007) and Devine et al. (2007a, 2007b) by illustrating the mixed, multidimensional experiences of culturally diverse migrant employees in the sector. 
The research reveals that a significant reason for entering the industry is for self development as migrants want to use and learn foreign languages, gain work experience and receive benefits that the industry may provide. Furthermore, due to the sectors' low skill requirements and subsequent accessibility, the sector facilitates migrants wanting or needing to enter into the labour market at the earliest opportunity. The research supports the concept of migrants seeking temporary work that is easily accessible and will give them opportunities to gain life experiences. For the short term, deciding to work in the sector is opportunistic due to the nature of the industry, rather than to facilitate any decisive or long term career development. Many migrants have the potential to be developed for more skilled occupations and longer term careers in the industry, but for many employees this is not their intention, and equally investing in human capital development largely is not the priority for many employers. Given the temporary nature of much of the migration, whilst the migrants' gain a new set of skills from their experience in the UK, it is not clear to what extent these will be used upon returning home. Certainly human capital developed on an individual basis is likely to have a subsequent impact on future career opportunities. At the micro level, when migration flows are followed by return migration, the benefits to the sending countries relate to the skills acquired abroad and the savings bought home by returning migrants (Lianos \& Pseiridis, 2009:155).

Once in the sector, many of the well-known features of the hospitality industry shape the migrants' experiences. The research suggests that migrants have a number of positive experiences associated with the industry, with opportunities to meet people and work in a good working environment being central. Other features raised by the respondents include the flexibility of the sector. This was important mainly for students as it suits their lifestyles and confirms previous research (Wildes, 2007) who demonstrate that a fun working environment is a motivating factor to remain in a job for the youngest employees of the restaurant industry, while those in their late 20s and 30s appreciated the flexibility that the sector offers.

Not surprisingly, there are a number of negative aspects related to hospitality working conditions identified by the respondents. This study reveals that the industry's image of being low paid and physically demanding holds true. Baum (2006) listed the popular perceptions of work in tourism and hospitality such as long difficult hours, dirty jobs, hard work, monotonous and boring work and many employees have to work standing. Some of these drawbacks were mentioned by the Polish employees. The exhausting long hours' culture was highlighted by migrants and includes physical tiredness, pain and health and safety issues pointing to the work and life unbalance (Karatepe \& Uludog 2007; Wong \& Ko 2009). Moreover, numerous problems were raised regarding poor 
management behaviour, lack of respect and drinking, discrimination, workload and problems with pay. This supports previous studies on international workers (Evans et al. 2007; Wright \& Pollert 2006; Wright 2007), and indicates that migrants from CEE countries, just like those with irregular status, experience problems. Subsequently, some of these issues contribute to the decision to leave. In many cases, hospitality jobs are seen as starter jobs and are envisaged for a limited period, which often suits both the workers and the employers. The findings support the notion that a negative image of hospitality jobs is only present in certain occupations (Riley, Ladkin, \& Szivas, 2002), and confirms Saunders' (1981) study of perceptions of kitchen porter jobs in hospitality as stigmatised. Interestingly, this image has not changed over time. For the reasons previously explained, this may not present problems for employers who had a continuous supply of migrant labour willing to do certain jobs in the short term.

The research highlights four human resource management issues. First, the flexible nature of hospitality may suit students or those who can work and study (Lucas, 2004) and therefore it is not necessarily a negative aspect. Shift work and weekend working may actually be of value for some workers, and rotas where possible could be aligned for preferences. This is also favourable to employers who can make use of the flexible working arrangements. The hospitality sector continues to employ a significant number of migrant workers and due to the nature of the demand for hospitality products and services, and many migrants' short stay plans, the relationship between employees and employers in this case is of mutual benefit (Lucas \& Mansfield, 2008).

Second, in terms of the perception of the industry, social interaction is without doubt one of the most important features of the hospitality industry that provides the positive side of hospitality work. In line with this research, others observed that dealing with people is one of the most commonly mentioned motives among those who moved to tourism jobs (Szivas, et al, 2003; Vaugeois \& Rollins, 2007; Lucas, 2004). This is clearly an attractive aspect of the industry and those employed in customer focussed jobs have opportunities for development that could encourage them to develop careers in the sector. Although many of the skills learned in customer focussed jobs and social interaction are intangible, clearly the migrants gain a life experience that can assist in their later career development upon returning home.

Third, on the negative side, the problems with pay reported here are not isolated. McDowell, Batnitzky and Dyer (2007) report that in a London hotel housekeepers' payment was based on the number of rooms cleaned in a specific time period, for example 16 rooms during a shift, allowing 2030 minutes per room. Wright and Pollert (2006) and Wright (2007) report some incidents of staff not being paid at all which was related to the legal/ informal status of migrant workers. Clearly all 
issues related to pay and discrimination indicates unacceptable working practices that tarnish the industry.

Fourth, in terms of recruitment, the image of the industry is problematic. The low status of many jobs and poor pay is widely known and efforts to recruit workers are notoriously difficult, especially for certain jobs. This combined with the Internet as a tool for the dissemination of information on jobs shows that experience can be shared at a global level. Both good and bad practice become much more widely known. Discussion boards may be used to help in recruitment strategies, especially for SMEs with smaller recruitment budgets and geographically isolated (Janta \& Ladkin, 2009). The use of the Internet among Polish users may be comparable to the increasingly popular 'blogging activity' among tourists who exchange information about tourism products through Tripadvisor, holidaycheck.com or travelpod (see Schmallegger \& Carson, 2008; Bosangit, McCabe \& Hibbert, 2009). While those tourists have an opportunity to rank a particular hotel and add a comment to advice potential consumers, previous and current hospitality employees use discussions' websites for the same purpose - to comment and made recommendations to potential employees. In both cases, on the travellers' websites as well as the Polish discussion boards, the content of these messages is loaded with a minimum level of moderation (Schmallegger \& Carson, 2008). Subsequently, these websites carry a great impact on the Internet users and influence customers' decision making process. Although a control of such discussions may be impossible, the managers should be aware that their employees are interacting with the Web 2.0 and are making their bad and good experiences public.

Overall, the findings from this research suggest that certain current practices and conditions in the sector are a clear obstacle for long term career commitment. Ironically, the availability of migrant workers does not help to improve working conditions (Baum, 2007). In fact, migrants may help to entrench certain employment practices that are favourable to employers. The features of the hospitality sector provide a framework of employment norms and conditions that thrive so long as migrant labour is readily available. Opinions on the sector's flexibility and jobs 'good initially' stress the fact that the occupation is treated as short term only. In the wider arena, the notion of temporariness is dominant in a number of recent studies concerned with migration from the new member states to the UK (Eade, Drinkwater, \& Garapich, 2006; Kosic, 2007; Anderson, et al. 2006; Spencer, et al. 2007) and is not unique to hospitality. In this context, working below qualification level is acceptable as long as it is for a short time period (Eade et al. 2006). In other words, migrants tolerate low skilled work and poor working conditions because they thereby improve English and expect to move into better jobs (Anderson et al. 2006). How these skills are used when the migrants 
return home is not known, but it is clear to see they develop human capital and produce individuals with increased international awareness, improved English language skills, experience and customer interaction. These skills are applicable to all industries and are not confined to tourism. On the downside, many of the skills learned are at a very low level. The findings from this research suggest that working in the hospitality sector is perceived by respondents as a temporary option before finding a job to follow as a long-term career. To date, no research has been undertaken on whether or not the returning migrants would consider working in the hospitality sector, or to develop careers elsewhere. The implications of this for the longer term development of the UK hospitality industry are open for debate and further research.

\section{References}

Anderson, B., Ruhs, M., Rogaly B., \& Spencer, S. (2006). 'Fair Enough? Central and East European Migrants in low-wage employment in the UK'. Report written for the Joseph Rowntree Foundation, published as a COMPAS Report. Available at: http://www.jrf.org.uk/sites/files/jrf/1617-migrantslow-wage-employment.pdf (Accessed: 29.06.2009).

Andriotis, K., and Vaughan. R. (2004) Exploring the assumptions using Crete as the case study. Current Issues in Tourism 7(1), 66-87.

Ashworth, J., \& Thomas, B. (1999). Patterns of seasonality in employment in tourism in the UK. Applied Economics, 6 (11), 735-739.

Aycan, Z., \& Berry, J.W. (1996). Impact of employment related experiences on immigrants' psychological well-being and adaptation to Canada. Canadian Journal of Behavioural Science 28(3):240-251.

Bauder, H. (2006). Origin, employment status and attitudes towards work: Immigrants in Vancouver, Canada. Work, Employment and Society, 20(4), 709-30.

Baum, T. (2006). Human Resource management for tourism, hospitality and leisure: An international perspective. Thomson Learning. London.

Baum, T. (2007). Human resources in tourism: Still waiting for change. Tourism Management, 28(6), 1383-1399.

Baum, T., Amoah, V., and Spivack,S. (1997). Policy dimensions of human resource management in the tourism and hospitality industries. International Journal of Contemporary Hospitality Management, 9(5/6), 221 - 229 
Baum, T., Dutton, E., Karimi, S., Kokkranikal, J. Devine, F. \& Hearns , N. (2007). Cultural diversity in hospitality work. Cross Cultural Management: An International Journal, 14(3), 229-239.

Baum, T., Hearns, N., \& Devine, F. (2008). Place branding and the representation of people at work: Exploring issues of tourism imagery and migrant labour in the Republic of Ireland. Place Branding and Public Diplomacy, 4, 45-60.

Beine, M., Docquier, F., \& Ozden, C. (2009). Diasporas. Policy Research Working Paper 4984. The World Bank. Available at the World Bank elibrary.

Bendyk, E. (2007). Polakow portret w sieci. Polityka, 43. Available at: http://technopolis.polityka.pl/2006/polakow-portret-z-sieci (Accessed 15.07.09).

Berg, B. L. (1994). Qualitative Research Methods for the social sciences. $\left(5^{\text {th }}\right.$ ed.). Allyn \& Bacon.

Bianchi, R. (2000). Migrant tourist-workers: Exploring the 'contact zones' of post-industrial tourism. Current issues in tourism, 3(2),107-137.

Bosangit, C., McCabea, S., \& Hibbert, S. (2009). What is Told in Travel Blogs? Exploring Travel Blogs for Consumer Narrative Analysis, in: Information and Communication Technologies in Tourism. Proceedings of the International Conference in Amsterdam, The Netherlands, Vienna: Springer.

Boyd D. M., \& Ellison, N.B. (2008). Social network sites: definition, history and scholarship. Journal of Computer-Mediated Communication, 13(1), 210-230.

Braun V., \& Clarke, V. (2006). Using thematic analysis in psychology. Qualitative research in Psychology, 3, 77-101.

Burns, P. M. (1997). Hard-skills, soft-skills: Undervaluating Hospitality's 'Service with a smile'. Progress in Tourism and Hospitality Research, 3, 239-248.

Choy, D. (1995) The quality of tourism employment. Tourism Management, 16 (2), 129-137.

Christensen-Hughes, J. (1992). Cultural Diversity: The Lesson of Toronto's Hotels. Cornell Hotel and Restaurant Administration Quarterly, 33 (2), 78-87.

Coles, T., Duval, D.T., \& Hall, C.M. (2005). Tourism, mobility and global communities. New approaches to theorising tourism and tourist spaces. In Theobald, W. (Ed.) Global Tourism. London: Elsevier. 
Creswell, J. W. (2009). Research design: qualitative, quantitative, and mixed method approaches. $\left(3^{\text {rd }}\right.$ ed.). London: Sage

Dench, S., Hurstfield, D., \& Akroyd, K. (2006). Employers' use of migrant labour. London: Home Office Report 04/06.

Denscombe, M. (2008). Communities of Practice: A Research Paradigm for the Mixed Methods Approach. Journal of Mixed Methods Research, 2 (3), 270-283.

Dermody, M.B., Young, M., \& Taylor, S.L . (2004). Identifying job motivation factors of restaurant servers: Insight for the development of effective recruitment and retention strategies. International Journal of Hospitality and Tourism Administration, 5 (3), 1-14.

Devine, F., Baum, T., Hearns, N., \& Devine, A. (2007a). Cultural diversity in hospitality work: the Northern Ireland experience. The International Journal of Human Resource Management, 18(2) 333 $-349$

Devine, F., Baum, T., Hearns, N., \& Devine, A. (2007b). Managing cultural diversity: opportunities and challenges for Northern Ireland hoteliers. International Journal of Contemporary Hospitality Management, 19 (2), 120-132.

Duncan, T., Scott, D. \& Baum T. (2009). The mobilities of hospitality work: an exploration of issues and debates. 27th International Labour Process Conference. Available at: http://www.ilpc.org.uk/Portals/56/ilpc2009-paperupload/ILPC2009paper-4071.doc (Last accessed 13th January 2010).

Duvall, D. T. (2004). 'When Buying into the Business, We Knew it was Seasonal': Perceptions of Seasonality in Central Otago, New Zealand. Int. Journal of Tourism Research, 6(5), 325-337.

Ellison, N. B., Steinfield, C., \& Lampe, C. (2007). The Benefits of Facebook 'Friends': Social Capital and College Students' Use of Online Social Network Sites. Journal of Computer-Mediated Communication, $12,1143-1168$.

Evans, Y, J., Wills, K., Datta, J., Herbert, C., Mcllwaine , C \& May, J. (2007). 'Subcontracting by stealth' in London's Hotels: impacts and implications for labour organising. Just Labour: A Canadian Journal of Work and Society, 10, 85-97.

Facebook Statistics (2010). http://www.facebook.com/press/info. Accessed 17 August 2010.

Faulkner B., \& Patiar, A. (1997). Workplace induced among operational staff in the hotel industry. International Journal of Hospitality Management, 16 (1), 99-117.

Fellini, I., Ferro, A., \& Fullin, G. (2007). Recruitment processes and labour mobility: The construction industry in Europe. Work, Employment and Society, 21(2), 277-98. 
Franklin, A., \& Crang, M. (2001). The trouble with tourism and travel theory. Tourist Studies, 1(1), 522.

Goldthorpe, J.H.D., Lockwood, F., Bechofer, \& Platt, J. (1968). The Affluent Worker: Industrial attitudes and behaviour. Cambridge: Cambridge University Press.

Hai-yan K., \& Baum, T. (2006). Skills and work in the hospitality sector. The case of hotel front office employees in China. International Journal of Contemporary Hospitality Management, 18 (6), 509-518.

Hall, C.M., \& Williams, A. (2002). Tourism and migration. New relationships between production and consumption. Dordrecht: Kluwer.

Hargittai E. (2008). Whose space? Differences among users and non-users of social network sites. Journal of Computer-Mediated Communication, 13(1), 276-297.

Hewson, C., Yule, P., Laurent, D., \& Vogel, C. (2003). Internet Research methods. A practical guide for the social and behavioural sciences. London: Sage.

Hinch, T. D., \& Jackson, E. L. (2000). Leisure Constraints Research: Its value as a framework for understanding tourism seasonality. Current issues in tourism, 3 (2), 87-106.

Home Office (2008). Accession Monitoring Report May 2004 - June 2008. Available at: http://www.ukba.homeoffice.gov.uk/sitecontent/documents/aboutus/reports/accession_monitorin g_report/

Home Office (2009). Accession Monitoring Report May 2004 - December 2008. Available at: http://www.ukba.homeoffice.gov.uk/sitecontent/documents/aboutus/reports/accession_monitorin g_report/report18/may04-dec08?view=Binary (Accessed 15.07.09).

Janta H., \& Ladkin, A. (2009). Polish migrant labour in the hospitality workforce: Implications for recruitment and retention'. Tourism, Culture and Communications, 9 (1/2), 5-15.

Jenkins, A. K. (2001). Making a career of it? Hospitality students' future perspectives: an Anglo-Dutch study. International Journal of Contemporary Hospitality Management, 13 (1), 13-20.

Jolliffe L., \& Farnsworth, A. (2003). Seasonality in tourism employment: human resource challenges. International Journal of Contemporary Hospitality Management, 15 (6), 312-316.

Karatepe, O. M., \& Uludag, O. (2007). Conflict, exhaustion, and motivation: A study of frontline employees in Northern Cyprus hotels. Hospitality Management, 26, 645-665. 
King R. (1995). Tourism, labour and international migration, In A. Montanari \& Williams, A.M.

European Tourism: Regions, Spaces and Restructuring: Chichester.

Kinnaird, V., Kothari, U., \& Hall, E. (1994). Tourism: A Gender Analysis. Chichester: Wiley.

Knocke, W. (2000). Integration or segregation? Immigration populations facing the labour market in Sweden. Economic and Industrial Democracy, 21(3), 361-80.

Kosic, A., Mannetti, L., \& Sam, D. L. (2005). Self-monitoring: A moderating role between acculturation strategies and adaptation of immigrants. International Journal of Intercultural Relations, 30, 141-157.

Kozinets, R. V. (2002). The field behind the screen: Using netnography for marketing research in Online communities. Journal of Marketing Research, 39(2), 61-72.

Krakover, S. (2000a). Partitioning seasonal employment in the hospitality industry. Tourism Management, 21(5), 461-471.

Krakover, S. (2000b). Seasonal adjustment of employment to demand and revenues in tourist hotels during expansion and stagnation. International Journal of Hospitality and Tourism Administration, 1 (2), 27-50.

Kroskrity, P. (2000). Identity. Journal of Linguistic Anthropology, 9 (1/ 2), 111- 114.

Kusluvan, S., \& Kusluvan, Z. (2000). Perceptions and attitudes of undergraduate tourism students towards working in the tourism industry in Turkey. Tourism Management, 21, 251-269.

Langer, R., \& Beckman, S.C. (2005). Sensitive research topics: netnography revisited. Qualitative Market Research: An International Journal, 8 (2), 189-203.

Lam T., Zhang, H., \& Baum, T. (2001). An investigation of employees' job satisfaction: the case of hotels in Hong Kong. Tourism Management, 22(2), 157-165.

Lee-Ross, D. (1999). Seasonal hotel jobs: an occupation and way of life. International Journal of Tourism Research, 1 (4), 239-154.

Lianos, T., \& Pseiridis, A. (2009). On the occupational choice of return migrants. Entrepreneurship and Regional Development, 21(2), 155-181.

Lucas, R. (2004). Employment relations in the hospitality and tourism industries, London: Routledge.

Lucas, R., \& Mansfield, S. (2008). Staff shortages and immigration in the hospitality sector. Web published by the Migration Advisory Committee. www.ukba.homeoffice/gov.uk/mac 
Lundmark, L. (2006.) Mobility, migration and seasonal tourism employment: Evidence from Swedish mountainm Municipalities. Scandinavian Journal of Hospitality and Tourism, 6 (3), 197-213.

Lundtorp, S., Rassing, C.R., \& Wanhill, S. (1999). The off-season is 'no-season': The case of the Danish island of Bornholm. Tourism Economics, 5 (1), 49-68.

Lyon, A., \& Sulcova, D. (2009). Hotel employer's perceptions of employing eastern European workers" A case study of Cheshire, UK. Tourism, Culture and Communication, 9(1/2), 17-28.

Mackenzie, R., \& Forde, C. (2009). The rhetoric of the 'good worker' versus the realities of employers' use and the experiences of migrant workers. Work, Employment and Society, 23(1), $142-$ 159.

Mars, G. Bryant D., \& Mitchell, P. (1979). Manpower problems in the hotel and catering industry, Gower: Farnborough.

Matthews, G., \& Ruhs, M. (2007). Are you being served? An exploration of the demand for migrant labour in the UK's hospitality sector. University of Oxford, Working Paper No. 51. Available at: http://www.compas.ox.ac.uk/research/Labour_market_and_Migration.shtml Available at: http://www.compas.ox.ac.uk/research/Labour_market_and_Migration.shtml (Accessed 03.06.08)

McDowell, L., Batnitzky, A., \& Dyer, S. (2008). Internationalization and the spaces of temporary labour: The global assembly of a local workforce. British Journal of Industrial Relations, 46 (4), pp.750-770.

Miles, M.B., \& Huberman, B. (1994). Qualitative data analysis. ( $2^{\text {nd }}$ ed.). London: Sage.

Nasza-klasa (2008). (our class) available at: www.nasza-klasa.pl

Nickson, D., Warhurst, C., \& Dutton, E. (2005). The importance of attitude and appearance in the service encounter in retail and hospitality. Managing Service Quality, 15(2), 195-208.

Phillimore, J., \& Goodson, L. (2008). New migrants in the UK. Education, training and employment. Stoke on Trent: Trentham Books.

Poulston, J. (2008) Hospitality employees' views on the unsatisfactory hygiene factors. Conference Proceedings of the 17th Annual CHME Research Conference, Glasgow, 516-530. 
Richardson, S. (2008). Undergraduates' perceptions of tourism and hospitality as a career choice. International Journal of Hospitality Management, 28 (3) 382-388.

Riley, M., Lockwood, A., Powell-Perry, J., \& Baker, M. (1998). Job Satisfaction, organisation commitment and occupational culture: A case from the UK pub industry. Progress in Tourism and Hospitality Research, 4, 159-168.

Riley, M., Ladkin, A., \& Szivas, E., (2002). Tourism employment. Analysis and planning. Clevedon: Channel View Publications.

Rodriguez, N. (2004). Workers wanted: Employer recruitment of immigrant labor. Work and Occupations, 31(4), 453-73.

Rowley G., \& Purcell, K. (2001) 'As cooks go, she went': is labour churn inevitable? International Journal of Hospitality Management, 20(2), 163-185.

Saunders, C. (1981). Social stigma of occupations: the lower grade worker in service organisations. Westmead: Gower.

Schonlau, M., Fricker, R. D., \& Elliott, M.N. (2002). Conducting research surveys via e-mail and the web Santa Monica, California: Rand.

Shaw, G., \& Williams, A.M. (1994). Critical issues in tourism: A geographical perspective, Blackwells: Oxford.

Shaw, G., \& Williams, A.M. (2002). Tourism employment and labour markets, in: Critical issues in Tourism: a geographical perspective, 165-187. Blackwells: Oxford.

Schmallegger, D., \& Carson, D. (2008). Blogs in tourism: Changing approaches to information exchange. Journal of Vacation Marketing, 14, 99-110.

Simons, T. , \& Enz C. A. (1995). Motivating hotel employees. Beyond the carrot and the stick. Cornell Hotel and Restaurant Administration Quarterly, 25(8), 678-685.

Spencer, S. , Ruhs, M., Anderson, B., \& Rogaly, B. (2007) Migrants' lives beyond the workplace: the experiences of Central and East in the UK, Joseph Rowntree Foundation.

Sue, V. M., \& Ritter, L.A. (2007). Conducting online surveys, Los Angeles; London: Sage.

Szivas, E., \& Riley, M. (1999). Tourism employment during economic transition. Annals of Tourism Research, 26 (4), 747-771. 
Szivas, E., Riley, M., \& Airey, D. (2003). Labour mobility into tourism. Attraction and satisfaction. Annals of Tourism Research, 30 (1), 64-75.

Trammell, K. D., Tarkowski, A., Hofmokl, J., \& Sapp, A. M. (2006). Rzeczpospolita blogów [Republic of Blog]: Examining Polish bloggers through content analysis. Journal of Computer-Mediated Communication, 11(3), article 2. Available at: http://jcmc.indiana.edu/vol11/issue3/trammell.html (Accessed: 07.07.09).

Uriely, N. (2001). Travelling workers and working tourists: variations across the interaction between work and tourism. International Journal of Tourism Research, 3 (1), 1-9.

Vaugeois, N., \& Rollins, N. (2007). Mobility into tourism: Refugee, employer? Annals of Tourism Research, 34 (3), 630-648.

Walmsley, A. (2004). Assessing staff turnover: a view from the English Riviera. International Journal of Tourism Research, 6 (4), 275-288.

Warhurst C.H., \& Nickson, D. (2007). Employee experience of aesthetic labour in retail and hospitality. Work, Employment and Society, 21(1), 103-120.

Wildes, V. (2005). Stigma in food service work: How it affects restaurant servers' intention to stay in the business or recommend a job to another. Tourism and Hospitality Research, 5 (3), 213-233.

Wildes, V. (2007). Attracting and retaining food serves: How internal service quality moderates occupational stigma. Journal of Hospitality Management, 26 1), 4-19.

Wong S. C, \& Ko, A. (2009). Exploratory study of understanding hotel employees' perception on work-life balance issues. International Journal of Hospitality Management 28(2), 195-203.

Wood, R. (1992). Working in Hotels and catering. London: Routledge.

Wright, T., \& Pollert, A. (2006). The experience of ethnic minority workers in the hotel and catering industry: Routes to support and advice on workplace problems. Research Paper, (Working Lives Research Institute, London Metropolitan University), Funded by Acas and the European Social Fund. Available at: http://www.acas.org.uk/media/pdf/0/b/03-06_1.pdf (Accessed 29.06.2009).

Żeromski, S., (1973) Opowiadania. Utwory powieściowe. (Ed. 5th). Warszawa: Czytelnik. 
